\title{
Segundo Protocolo de la Convención de La Haya de 1954 para la Protección de los Bienes Culturales en caso de Conflicto Armado
}

En el número 28 de $\mathrm{PH}$. Boletín del Instituto Andaluz del Patrimonio Histórico, correspondiente al tercer trimestre de 1999 dábamos a conocer los trabajos que tuvieron lugar entre mayo de 1998 y marzo de 1999, bajo los auspicios de la UNESCO, y que dieron como resultado la formulación y aprobación, en una Conferencia Internacional convocada al efecto, de un segundo Protocolo anexo a la Convención de La Haya para la protección de bienes culturales en caso de conflicto armado.

Como se recordará, en aquella noticia nos comprometíamos a ofrecer en el número 29 de $\mathrm{PH}$ la versión española de dicho Protocolo. No obstante las gestiones realizadas, no fue posible obtener la versión oficial en castellano del Protocolo hasta finales de diciembre de 1999, cuando ya estaba cerrada la edición del Boletín 29. Por esta razón incluimos en este número la primera mitad del texto normativo con el que hacemos frente a nuestro compromiso, no sin antes haber ofrecido a los lectores de $\mathrm{PH}$ esta explicación.

Lorenzo Pérez del Campo Jefe del Centro de Intervención del IAPH

\section{La Haya, 26 de marzo de 1999}

\section{Las Partes,}

Conscientes de la necesidad de mejorar la protección de los bienes culturales en caso de conflicto armado y de establecer un sistema reforzado de protección para bienes culturales especialmente designados;

Reiterando la importancia de las disposiciones de la Convención para la Protección de los Bie- nes Culturales en caso de Conflicto Armado adoptada en La Haya el 14 de mayo de 1954, y haciendo hincapié en la necesidad de completar esas disposiciones con medidas que refuercen su aplicación;

Deseosas de proporcionar a las Altas Partes Contratantes en la Convención un medio para participar más estrechamente en la protección de los bienes culturales en caso de conflicto armado mediante el establecimiento de procedimientos adecuados;

Considerando que las reglas que rigen la protección de los bienes culturales en caso de conflicto armado deberían reflejar la evolución del derecho internacional;

Afirmando que las reglas del derecho internacional consuetudinario seguirán rigiendo las cuestiones no reguladas en las disposiciones del presente Protocolo, han convenido en lo siguiente:

\section{Capítulo I: Introducción}

Artículo I: Definiciones

A los efectos del presente Protocolo:

a) Por "Parte" se entenderá un Estado Parte en el presente Protocolo;

b) Por "Bienes Culturales" se entenderán los bienes culturales definidos en el Artículo I de la Convención;

c) Por "Convención" se entenderá la Convención para la Protección de los Bienes Culturales en caso de Conflicto Armado, adoptada en La Haya el 14 de mayo de 1954; d) Por "Alta Parte Contratante" se entenderá un Estado Parte en la Convención;

e) Por "Protección Reforzada" se entenderá el sistema de protección reforzada establecido en los Artículos 10 y II;

f) Por "Objetivo Militar" se entenderá un objeto que por su naturaleza, ubicación, finalidad o utilización, contribuye eficazmente a la acción militar y cuya destrucción total o parcial, captura o neutralización ofrece en las circunstancias del caso una ventaja militar definida;

g) Por "lííito" se entenderá realizado bajo coacción o de otra manera, en violación de las reglas aplicables de la legislación nacional del territorio ocupado o del derecho internacional;

h) Por "Lista" se entenderá la Lista Internacional de Bienes Culturales bajo Protección Reforzada establecida con arreglo al apartado b) del párrafo I del Artículo 27;

i) Por "Director General" se entenderá el Director General de la UNESCO;

j) Por "UNESCO" se entenderá la Organización de las Naciones Unidas para la Educación, la Ciencia y la Cultura.

k) Por "Primer Protocolo" se entenderá el Protocolo para la Protección de los Bienes Culturales en caso de Conflicto Armado adoptado en La Haya el 14 de mayo de 1954;

\section{Artículo 2: Relación con la Convención}

El presente Protocolo complementa a la Convención en lo relativo a las relaciones entre las Partes. 


\section{Artículo 3: Ámbito de aplicación}

I. Además de las disposiciones que se aplican en tiempo de paz, el presente Protocolo se aplicará en las situaciones previstas en los párrafos 1 y 2 del Artículo 18 de la Convención y en el párrafo I del Artículo 22.

2. Si una de las partes en un conflicto armado no está obligada por el presente Protocolo, las Partes en el presente Protocolo seguirán obligadas por él en sus relaciones recíprocas. Asimismo, estarán obligadas por el presente Protocolo en sus relaciones con un Estado parte en el conflicto que no esté obligado por él, cuando ese Estado acepte sus disposiciones y durante todo el tiempo que las aplique.

\section{Artículo 4: Relaciones entre el Capítulo 3 y otras disposiciones de la Convención y del presente Protocolo}

Las disposiciones del Capítulo 3 del presente Protocolo se aplicarán sin perjuicio de:

a) la aplicación de las disposiciones del Capítulo I de la Convención y del Capítulo 2 del presente Protocolo;

b) la aplicación de las disposiciones del Capítulo II de la Convención entre las Partes del presente Protocolo o entre una Parte y un Estado que acepta y aplica el presente Protocolo con arreglo al párrafo 2 del Artículo 3 , en el entendimiento de que si a un bien cultural se le ha otorgado a la vez una protección especial y una protección reforzada, sólo se aplicarán las disposiciones relativas a la protección reforzada.

\section{Capítulo 2 : Disposiciones generales relativas a la protección}

Artículo 5: Salvaguardia de los bienes culturales
Las medidas preparatorias adoptadas en tiempo de paz para salvaguardar los bienes culturales contra los efectos previsibles de un conflicto armado conforme al Artículo 3 de la Convención comprenderán, en su caso, la preparación de inventarios, la planificación de medidas de emergencia para la protección contra incendios o el derrumbamiento de estructuras, la preparación del traslado de bienes culturales muebles o el suministro de una protección adecuada in situ de esos bienes, y la designación de autoridades competentes que se responsabilicen de la salvaguardia de los bienes culturales.

\section{Artículo 6: Respeto de los bienes culturales}

A fin de garantizar el respeto de los bienes culturales de conformidad con el Artículo 4 de la Convención:

a) una derogación fundada en una necesidad militar imperativa conforme al párrafo 2 del Artículo 4 de la Convención sólo se podrá invocar para dirigir un acto de hostilidad contra un bien cultural cuando y durante todo el tiempo en que:

i) ese bien cultural, por su función, haya sido transformado en un objetivo militar; $y$

ii) no exista otra alternativa prácticamente posible para obtener una ventaja militar equivalente a la que ofrece el hecho de dirigir un acto de hostilidad contra ese objetivo;

b) una derogación fundada en una necesidad militar imperativa conforme al párrafo 2 del Artículo 4 de la Convención sólo se podrá invocar para utilizar bienes culturales con una finalidad que pueda exponerles a la destrucción o al deterioro cuando y durante todo el tiempo en que resulte imposible elegir entre esa utilización de los bienes culturales y otro método factible para obtener una ventaja militar equivalente;

c) la decisión de invocar una necesidad milltar imperativa solamente será tomada por el oficial que mande una fuerza de dimensión igual o superior a la de un bata- llón, o de menor dimensión cuando las circunstancias no permitan actuar de otra manera;

d) en caso de ataque basado en una decisión tomada de conformidad con el apartado a) se debe dará aviso con la debida antelación y por medios eficaces, siempre y cuando las circunstancias lo permitan.

\section{Artículo 7: Precauciones en el ataque}

Sin perjuicio de otras precauciones exigidas por el derecho internacional humanitario en la conducción de operaciones militares, cada Parte en el conflicto debe:

a) hacer todo lo que sea factible para verificar que los objetivos que se van a atacar no son bienes culturales protegidos en virtud del Artículo 4 de la Convención:

b) tomar todas las precauciones factibles en la elección de los medios y métodos de ataque para evitar $y$, en todo caso, reducir lo más posible los daños que se pudieran causar incidentalmente a los bienes culturales protegidos en virtud del Artículo 4 de la Convención;

c) abstenerse de decidir un ataque cuando sea de prever que causará incidentalmente daños a los bienes culturales protegidos en virtud del Artículo 4 de la Convención, que serían excesivos en relación con la ventaja militar concreta y directa prevista; $y$

d) suspender $\mathrm{o}$ anular un ataque si se advierte que:

i) el objetivo es un bien cultural protegido en virtud del Artículo 4 de la Convención;

ii) es de prever que el ataque causará incidentalmente daños a los bienes culturales protegidos en virtud del Artículo 4 de la Convención, que serían excesivos en relación con la ventaja militar concreta y directa prevista; 


\section{Noticias y Comentarios}

\section{Artículo 8: Precauciones contra los efectos de las hostilidades}

En toda la medida de lo posible, las Partes en conflicto deberán:

a) alejar los bienes culturales muebles de las proximidades de objetivos militares o suministrar una protección adecuada in situ;

b) evitar la ubicación de objetivos militares en las proximidades de bienes culturales.

\section{Artículo 9: Protección de bienes culturales en territorio ocupado}

1. Sin perjuicio de las disposiciones de los Artículos 4 y 5 de la Convención, toda Parte que ocupe total o parcialmente el territorio de otra Parte prohibirá e impedirá con respecto al territorio ocupado:

a) toda exportación y cualquier otro desplazamiento o transferencia de propiedad ilícitos de bienes culturales;

b) toda excavación arqueológica, salvo cuando sea absolutamente indispensable para salvaguardar, registrar o conservar bienes culturales;

c) toda transformación o modificación de la utilización de bienes culturales con las que se pretenda ocultar o destruir testimonios de índole cultural, histórica o científica.

Toda excavación arqueológica, transformación o modificación de la utilización de bienes culturales en un territorio ocupado deberá efectuarse, a no ser que las circunstancias no lo permitan, en estrecha cooperación con las autoridades nacionales competentes de ese territorio ocupado.

\section{Capítulo 3 : Protección reforzada}

\section{Artículo 10: Protección reforzada}

Un bien cultural podrá ponerse bajo protección reforzada siempre que cumpla las tres condiciones siguientes:

a) que sea un patrimonio cultural de la mayor importancia para la humanidad; b) que esté protegido por medidas nacionales adecuadas, jurídicas y administrativas, que reconozcan su valor cultural e histórico excepcional y garanticen su protección en el más alto grado; $y$

c) que no sea utilizado con fines militares o para proteger instalaciones militares, y que haya sido objeto de una declaración de la Parte que lo controla, en la que se confirme que no se utilizará para esos fines.

\section{Artículo II: Concesión de la protección reforzada}

I. Cada Parte someterá al Comité una lista de los bienes culturales para los que tiene intención de solicitar la concesión de la protección reforzada.

2. La Parte bajo cuya jurisdicción o control se halle un bien cultural podrá pedir su inscripción en la Lista que se establecerá en virtud del apartado b) del párrafo I del Artículo 27. Esta petición comprenderá toda la información necesaria relativa a los criterios mencionados en el Artículo 10. El Comité podrá invitar a una Parte a que pida la inscripción de ese bien cultural en la Lista.

3. Otras Partes, el Comité Internacional del Escudo Azul y otras organizaciones no gubernamentales con la competencia apropiada podrán recomendar al Comité un bien cultural específico. En ese caso, el Comité podrá tomar la decisión de invitar a una Parte a que pida la inscripción de ese bien cultural en la Lista.

4. Ni la petición de inscripción de un bien cultural situado en un territorio, bajo una soberanía o una jurisdicción que reivindiquen más de un Estado, ni la inscripción de ese bien perjudicarán en modo alguno los derechos de las partes en litigio.

5. Cuando el Comité reciba una petición de inscripción en la Lista, informará de ella a todas las Partes. En un plazo de sesenta días, las Partes podrán someter al Comité sus alegaciones con respecto a esa petición. Esas alegaciones se fundarán exclusivamente en los criterios mencionados en el Artículo 10. Deberán ser precisas y apoyarse en hechos. El Comité examinará esas alegaciones y proporcionará a la Parte que haya pedido la ins- cripción una posibilidad razonable de responder antes de que se tome la decisión. Cuando se presenten esas alegaciones al Comité, las decisiones sobre la inscripción en la Lista se tomarán, no obstante lo dispuesto en el Artículo 26, por mayoría de las cuatro quintas partes de los miembros del Comité presentes y votantes.

6. Al tomar una decisión sobre una petición, el Comité procurará solicitar el dictamen de organizaciones gubernamentales y no gubernamentales, así como el de expertos particulares.

7. La decisión de conceder o negar la protección reforzada sólo se puede basar en los criterios mencionados en el Artículo 10.

8. En casos excepcionales, cuando el Comité ha llegado a la conclusión de que la Parte que pide la inscripción de un bien cultural en la Lista no puede cumplir con el criterio del párrafo b) del Artículo 10, podrá tomar la decisión de conceder la protección reforzada siempre que la Parte solicitante someta una petición de asistencia internacional en virtud del Artículo 32

9. Desde el comienzo de las hostilidades, una Parte en el conflicto podrá pedir, por motivos de urgencia, la protección reforzada de los bienes culturales bajo su jurisdicción o control, sometiendo su petición al Comité. El Comité transmitirá inmediatamente esta demanda a todas las Partes en el conflicto. En ese caso, el Comité examinará urgentemente las alegaciones de las Partes interesadas. La decisión de conceder la protección reforzada con carácter provisional se tomará con la mayor rapidez posible y, no obstante lo dispuesto en el Artículo 26, por mayoría de las cuatro quintas partes de los miembros del Comité presentes y votantes. El Comité podrá conceder la protección reforzada, a la espera del resultado del procedimiento normal de concesión de dicha protección, siempre que se cumpla con las disposiciones de los párrafos a) y c) del Artículo 10.

10. El Comité concederá la protección reforzada a un bien cultural a partir del momento en que se inscriba en la Lista.

I I. El Director General notificará sin espera al Secretario General de las Naciones Unidas y a todas las Partes toda decisión del Comité relativa a la inscripción de un bien cultural en la Lista. 


\section{Artículo 12: Inmunidad de los bienes culturales bajo protección reforzada}

Las Partes en un conflicto garantizarán la inmunidad de los bienes culturales bajo protección reforzada, absteniéndose de hacerlos objeto de ataques y de utilizar esos bienes o sus alrededores inmediatos en apoyo de acciones militares.

\section{Artículo 13: Pérdida de la protección reforzada}

1. Los bienes culturales bajo protección reforzada sólo perderán esa protección:

a) cuando esa protección se anule o suspenda en virtud del Artículo 14; o

b) cuando y durante todo el tiempo en que la utilización del bien lo haya convertido en un objetivo militar

2. En las circunstancias previstas en el apartado b) del párrafo I, ese bien sólo podrá ser objeto de un ataque:

a) cuando ese ataque sea el único medio factible para poner término a la utilización de ese bien mencionada en el apartado b) del párrafo I;

b) cuando se hayan tomado todas las precauciones prácticamente posibles en la elección de los medios y métodos de ataque, con miras a poner término a esa utilización y evitar, o en todo caso reducir al mínimo, los daños del bien cultural.

c) cuando, a menos que las circunstancias no lo permitan, por exigencias de legítima defensa inmediata:

i) el ataque haya sido ordenado por el nivel más alto del mando operativo;

ii) se haya dado un aviso con medios eficaces a las fuerzas adversarias, instándolas a poner un término a la utilización mencionada en el apartado b) del párrafo I; y

iii) se haya concedido un plazo razonable a las fuerzas adversarias para regularizar la situación.

\section{Artículo 14: Suspensión y anulación de la protección reforzada}

I. Cuando un bien cultural no satisfaga alguno de los criterios enunciados en el Artículo 10 del pre- sente Protocolo, el Comité podrá suspender o anular su protección reforzada retirándolo de la Lista.

2. En caso de violaciones graves del Artículo 12 por utilización de bienes culturales bajo protección reforzada en apoyo de una acción militar, el Comité podrá suspender la protección reforzada de esos bienes. Cuando esas violaciones sean continuas, el Comité podrá excepcionalmente anular su protección reforzada retirándolo de la Lista.

3. El Director General notificará sin demora al Secretario General de las Naciones Unidas y a todas las Partes en el presente Protocolo toda decisión del Comité relativa a la suspensión o anulación de la protección reforzada de un bien cultural.

4. Antes de tomar una decisión de esta índole, el Comité ofrecerá a las Partes la posibilidad de que den a conocer sus pareceres.

\section{Capítulo 4: Responsabilidad penal y jurisdicción}

\section{Artículo 15: Violaciones graves del presente Protocolo}

I. Cometerá una infracción en el sentido de este Protocolo toda persona que, deliberadamente y en violación de la Convención o del presente Protocolo, realice uno de los siguientes actos:

a) hacer objeto de un ataque a un bien cultural bajo protección reforzada;

b) utilizar los bienes culturales bajo protección reforzada o sus alrededores inmediatos en apoyo de acciones militares;

c) causar destrucciones importantes en los bienes culturales protegidos por la Convención y el presente Protocolo o apropiárselos a gran escala;

d) hacer objeto de un ataque a un bien cultural protegido por la Convención y el presente Protocolo;

e) robar, saquear o hacer un uso indebido de los bienes culturales protegidos por la Convención y perpetrar actos de vandalismo contra ellos.

2. Cada Parte adoptará las medidas que sean necesarias para tipificar como delitos, con arreglo a su legislación nacional, las infracciones indicadas en el presente Artículo, y para sancionar esas infracciones con penas adecuadas. Al hacer esto, las Partes se conformarán a los principios generales del derecho y del derecho internacional, comprendidas las normas que hacen extensible la responsabilidad penal individual a personas que no han sido autoras directas de los actos.

\section{Artículo 16: Jurisdicción}

I. Sin perjuicio de lo dispuesto en el párrafo 2 , cada Parte adoptará las medidas legislativas necesarias para establecer su jurisdicción respecto de las infracciones indicadas en el Artículo 15, en los siguientes casos.

a) cuando la infracción se haya cometido en el territorio de este Estado;

b) cuando el presunto autor sea un nacional de este Estado;

c) cuando se trate de las infracciones indicadas en los apartados a) a c) del primer párrafo del Artículo 15, en caso de que el presunto autor esté presente en el territorio de este Estado;

2. Con respecto al ejercicio de la jurisdicción, y sin perjuicio de lo dispuesto en el Artículo 28 de la Convención:

a) el presente Protocolo no excluye que se pueda incurrir en responsabilidad penal individual ni que se ejerza la jurisdicción en virtud del derecho nacional e internacional aplicable, y tampoco afecta al ejercicio de la jurisdicción en virtud del derecho internacional consuetudinario;

b) excepto en el caso en que un Estado que no es Parte en el presente Protocolo pueda aceptarlo y aplicar sus disposiciones con arreglo al párrafo 2 del Artículo 3, los miembros de las fuerzas armadas y los nacionales de un Estado que no es Parte en el presente Protocolo, salvo aquellos de sus nacionales que sirven en las fuerzas armadas de un Estado que es Parte en el presente Protocolo, no incurrirán en responsabilidad penal individual en virtud del presente Protocolo, que además no impone ninguna obligación relativa al establecimiento de jurisdicción con respecto a esas personas ni a su extradición. 